\title{
Non-cross-linked biological mesh in complex abdominal wall hernia: a cohort study
}

\author{
Ruth Kaufmann ${ }^{1,2}$ (D) $\cdot$ Friedrich-Eckart Isemer ${ }^{3,4} \cdot$ Christoph W. Strey $^{5}$ (D) $\cdot$ Johannes Jeekel $^{6}$ (D) Johan F. Lange ${ }^{1}$. \\ Guido Woeste 7,8
}

Received: 25 April 2019 / Accepted: 7 April 2020 / Published online: 22 April 2020

(C) The Author(s) 2020

\begin{abstract}
Purpose Complex abdominal wall hernia repair (CAWHR) is a challenging procedure. Mesh prosthesis is indicated, but the use of synthetic mesh in a contaminated area may add to overall morbidity. Biological meshes may provide a solution, but little is known about long-term results. The aim of our study was to evaluate clinical efficacy and patient satisfaction following Strattice ${ }^{\mathrm{TM}}$ (PADM) placement.

Methods In this cohort study, all patients operated for CAWHR with PADM in three large community hospitals in Germany were included. Patients underwent abdominal examination, an ultrasound was performed, and patients completed quality-of-life questionnaires. The study was registered in ClinicalTrials.gov under Identifier NCT02168231.

Results Twenty-seven patients were assessed (14 male, age 67.5 years, follow-up 42.4 months). The most frequent postoperative complication was wound infection (39.1\%). In no case, the PADM had to be removed. Four patients had passed away. During outpatient clinic visit, six out of 23 patients $(26.1 \%)$ had a recurrence of hernia, one patient had undergone reoperation. Five patients $(21.7 \%)$ had bulging of the abdominal wall. Quality-of-life questionnaires revealed that patients judged their scar with a median 3.5 out of 10 points $(0=$ best $)$ and judged their restrictions during daily activities with a median of 0 out of $10.0(0=$ no restriction).

Conclusions Despite a high rate of wound infection, no biological mesh had to be removed. In some cases, therefore, the biological meshes provided a safe way out of desperate clinical situations. Both the recurrence rate and the amount of bulging are high (failure rate $47.8 \%$ ). The reported quality of life is good after repair of these complex hernias.
\end{abstract}

Keywords Complex abdominal wall hernia $\cdot$ Non-cross-linked biological mesh $\cdot$ Long-term results

Ruth Kaufmann

ruth.kaufmann@gmail.com; r.kaufmann@erasmusmc.nl

Friedrich-Eckart Isemer

isemerfe@hotmail.com

Christoph W. Strey

strey@gmx.de

Johannes Jeekel

j.jeekel@erasmusmc.nl

Johan F. Lange

j.lange@erasmusmc.nl

Guido Woeste

woeste.guido@eke-da.de

1 Department of Surgery, Erasmus University Medical Center, Room Ee-173, Wytemaweg 80, NL-3015 CN Rotterdam, The Netherlands
2 Department of Radiology, Haga Teaching Hospital, The Hague, The Netherlands

3 Department of General and Trauma Surgery, St. Josefs-Hospital, Wiesbaden, Germany

4 Hernienzentrum DKD HELIOS-Klinik, Wiesbaden, Germany

5 Department of General, Visceral, and Vascular Surgery, Diakoniekrankenhaus Friederikenstift gGmbH, Hannover, Germany

6 Department of Neuroscience, Erasmus University Medical Center, Rotterdam, The Netherlands

7 Department of General and Visceral Surgery, Klinikum der Johann Wolfgang Goethe Universität Frankfurt, Frankfurt am Main, Germany

8 Department of General and Visceral Surgery, Agaplesion Elisabethenstift gGmbH, Darmstadt, Germany 


\section{Introduction}

Incisional hernia is a common complication after abdominal surgery. Incidences range from 3 to $20 \%$ in the general population [1-7] with an increased incidence of 26 up to $39 \%$ in patients suffering of obesity or aortic aneurysms [2, 7-19]. Currently, incisional hernias are most often reinforced with mesh material $[20,21]$. The use of mesh radically lowered the 10-year recurrence rates after incisional hernia repair [20]. There are various mesh prosthesis available (conventional synthetic meshes, biological meshes, and since recently also biosynthetic meshes (i.e., slowly resorbable synthetic meshes)) [22-24]. Conventional synthetic meshes are still used most often in general practice, and polypropylene mesh is the most popular product [25].

There are various reasons, like mesh infections, enterocutaneous fistulas, burst abdomen, and anastomotic leakage, that could turn an 'uncomplicated' ventral hernia repair into a complex abdominal wall hernia repair (CAWHR) [26].

The grade of contamination is an important factor in the treatment of incisional hernia. To classify the amount of contamination, the Ventral Hernia Working Group (VHWG) developed a hernia grading system to classify the different grades of contamination and its treatment complexity in abdominal wall hernia repair (grade 1: low risk to grade 4: infected) [27]. In potentially contaminated and infected incisional hernia the use of conventional synthetic mesh is controversial and might lead to a higher morbidity and even mortality. In case of an infected synthetic mesh, the mesh should be removed completely to achieve complete wound healing [28]. Patients often have multiple comorbidities and risk factors that increase the risk for postoperative complications and hernia recurrence. In order to provide the safest individual treatment strategies to high morbidity patients, a classification for complex abdominal wall hernias was defined to facilitate the choice for CAWHR concepts [29].

Patients who need CAWHR often undergo strictly planned, staged repair of their hernia defect [30]. Part of a different treatment strategy for CAWHR is the use of biological mesh instead of synthetic mesh in a one-stage procedure. Biological mesh is however only seldom used, since costs per prosthesis are high and little is known about long-term results. In this study, the use of Strattice ${ }^{\mathrm{TM}}$ mesh was evaluated. Strattice ${ }^{\mathrm{TM}}$ is a decellularized, intact, non-cross-linked porcine acellular dermal matrix, derived from porcine dermis [31]. The study is initiated after a nationwide German questionnaire of the ROKI Group [32]. The aim of this study was to evaluate clinical efficacy and patient satisfaction following Strattice ${ }^{\mathrm{TM}}$ placement in patients treated for CAWHR in three academic and peripheral hospitals in Germany. In this study, Strattice ${ }^{\mathrm{TM}}$ is referred to as non-cross-linked porcine acellular dermal matrix (PADM).

\section{Material and methods}

\section{Study design}

A cohort study was performed in three large community hospitals in Germany (both academic and peripheral centers). Patients were identified retrospectively and were invited to an outpatient clinic appointment. Ethical approval for this study was obtained from the Ethics Board of the Johann Wolfgang Goethe University Frankfurt, Germany. After ethical approval from the Johann Wolfgang Goethe University Frankfurt, ethical approval was obtained from all local ethical committees in the participating hospitals.

\section{Patients}

Patients were eligible for inclusion in the cohort if they had been operated with PADM for the indication CAWHR in one of the participating centers in Germany. CAWHR was defined as the repair for a potentially contaminated to infected hernia, which is grade 3 to grade 4 according to the system developed by the VHWG [27]. Patients had to provide written informed consent to participate in the study.

\section{Procedure}

Patients were identified by the surgeons of the participating centers. The surgeons contacted all their patients and gave them - if they were interested - additional information about participation in the study. After written informed consent was obtained, patients were invited to an appointment in the outpatient clinic.

Patients were interviewed to collect baseline parameters, and to assess their medical history. Baseline parameters were defined as age, gender, BMI, severity of co-morbidity score [33], length of follow-up, smoking history, and occupational heavy lifting. The assessment of their medical history focused on medical conditions like COPD/chronic coughing, steroid use, malignancy, diabetes, general abdominal operations, and specific abdominal wall operations.

All patients underwent abdominal wall examination to assess the presence of a hernia recurrence or bulging of the abdominal wall. An abdominal wall ultrasound was performed in case of doubt. Patients completed quality-of-life questionnaires to assess patient satisfaction. The EuraHS quality-of-life questionnaires were used to assess patients' quality of life [33, 34]. The STROBE statement was followed [35].

The acquired data was registered in the standardized case record forms of the incisional ventral hernia route in the EuraHS Database (http://www.eurahs.eu/). These case record forms were registered in a private group and were only accessible to the members of this study group. 


\section{Outcomes}

The primary outcome for this study was recurrence of hernia and / or the bulging of the abdominal wall after PADM repair. Both incisional hernia and the recurrence of incisional hernia were defined as any abdominal wall gap with or without bulge in the area of a postoperative scar perceptible or palpable by clinical examination or medical imaging [36]. Bulging of the abdominal wall was defined as a substantial increase in abdominal circumference, not explicable by weight gain, in the absence of a palpable or objectifiable fascia defect, and observed by either the patient or the doctor [37-39]. All patients were diagnosed by clinical examination. In case of doubt, abdominal wall medical imaging (i.e., ultrasound and/or CT scan) was performed to confirm or reject the diagnosis.

Secondary outcomes in this study included postoperative complications, i.e., wound infection, mesh infection, intraabdominal and/or skin abscess, seroma, hematoma, necrotic abdominal wall, fistulas, and burst abdomen. The occurrence of mesh explantation was also recorded, just like additional abdominal operations, and quality-of-life parameters. Complications were classified according to Dindo and Clavien [40].

\section{Statistical analysis}

Continuous variables were summarized by using means and ranges; categorical values were summarized with frequencies and percentages. Quality-of-life questionnaires were summarized with medians and ranges. The database was made in Microsoft Excel version 2016 (MSO 16.0.11029.20045) and analyzed in SPSS version 26.0 (version 26.0.0.0). The data was assessed for normality by performing a Shapiro-Wilk's test $(p>0.05)$, and a visual inspection of their histograms, normal Q-Q plots, and box plots showed that most of the data was approximately normally distributed. Thereafter, the skewness and kurtosis of the data were calculated. If the Z-values were in the desired range of -1.96 to 1.96 , the data was presented as median (range). If the data was not normally distributed, it was presented as median (interquartile ranges). There was no data safety committee overseeing the study. The study was registered in ClinicalTrials.gov under Identifier NCT02168231.

\section{Role of the funding source}

Funding to execute this study was obtained from LifeCell Corporation, a KCI company, Branchburg, NJ, USA. The funder of the study had no role in study design, data collection, data analysis, data interpretation, or writing of the report. The corresponding author had full access to all the data in the study and had final responsibility for the decision to submit for publication.

\section{Results}

\section{Patients characteristics}

A total of 27 patients met the inclusion criteria, of whom four were deceased. These four patients had passed away after surgery after 5, 22, 50, and 904 days, respectively. Twentythree patients have been assessed for long-term follow-up (14 male, mean age 67.5 years, mean follow-up 42.4 months). Their median BMI was 27.4 (interquartile range 24.1-32.2). The median SOC score was 2 for all registered comorbidities (Table 1).

\section{Perioperative information}

The risk factor seen most often was a personal history of previous abdominal wall hernia operation (Table 2). The estimated diameter of the hernia was median $18.25 \mathrm{~cm}$ (range 10 $30 \mathrm{~cm}$ ). The median defect size of the hernia was $357 \mathrm{~cm}^{2}$ (range $100-900 \mathrm{~cm}^{2}$ ). The operation was elective in 16 patients, and an emergency procedure in five patients. In two patients, it was unknown whether it was an elective or an emergency procedure. All perioperative information was recorded retrospectively and whenever possible verified with patients during their outpatient visit.

The hernia was located most often in the midline in the areas M2, M3, M4, and M5. Only three patients had undergone a previous hernia repair. These patients had undergone a median number of two previous hernia repairs (range one to three operations). All patients were operated under general anesthesia. Most patients received a single dose of antibiotics preoperatively $(n=11)$. In none of the patients, preoperative botulinum toxin or progressive preoperative pneumoperitoneum was used.

The wound classification was median CDC wound class III (contaminated) [41, 42]. In ten patients, a part of the bowel had to be removed during operation. The abdomen was closed with a combined component separation and mesh placement in 15 patients. In eight patients, mesh repair sufficed. All patients received a Strattice ${ }^{\mathrm{TM}}$ mesh. The most frequently used mesh size was $400 \mathrm{~cm}^{2}$. The mesh was fixated with transfascial sutures, and the entire hernia defect could be closed in all patients. There were no intraoperative surgical complications. The median length of stay after operation was 15 days (range $7-124$ days).

\section{Postoperative outcomes}

The most frequent postoperative complication was wound infection $(39.1 \%)$. In six patients, it was a superficial wound infection. In no case, the PADM had to be removed. Other intrahospital complications were a bleeding complication in one patient, and in three patients there were general 
Table 1 Baseline criteria

\begin{tabular}{ll}
\hline Mean follow-up (mean) & 42.4 months \\
Gender: male vs. female & 14 vs. 9 \\
Age (mean) (range) & 67.5 years (48-90) \\
BMI (median) (interquartile range) & $27.4(24.1-32.2)$ \\
SOC score (median) (range) & $2(1-3)$ \\
Comorbidities (number of patients (percentage)) & \\
Arterial hypertension & $9(39.1 \%)$ \\
Cardiac disease & $6(26.1 \%)$ \\
Diabetes mellitus type II & $8(34.8 \%)$ \\
Malignant disease & $2(8.7 \%)$ \\
Pulmonary disease (COPD/asthma) & $3(13 \%)$ \\
Renal disease & $5(21.7 \%)$ \\
Other: peritonitis, fistula, cachexia, hypothyroidism, portal vein thrombosis & $8(34.8 \%)$ \\
No comorbidities & $5(21.7 \%)$ \\
Smoking (daily/occasional smoking) & $6(26.1 \%)$ \\
Ex-smoker & $7(30.4 \%)$ \\
\hline
\end{tabular}

complications (acute renal failure, pleural effusion, peritonitis). In five patients, there were no intrahospital complications. The classification of the complications according to Dindo and Clavien was median grade IIIb (intervention under general anesthesia) [40].

\section{Long-term outcomes}

By the time of outpatient clinic visit, six out of 23 patients (26.1\%) had a recurrence of hernia, of whom one patient had undergone reoperation. All recurrences were found at the original hernia site. Another five patients $(21.7 \%)$ had an asymptomatic bulging of the abdominal wall. Fourteen patients $(60.1 \%)$ were evaluated by clinical examination combined with medical imaging, seven patients $(30.4 \%)$ were evaluated with clinical examination, and in two patients $(8.7 \%)$, it was unknown whether clinical examination was used with or without medical imaging. Patients with a recurrence or bulging often wore an abdominal binder.

Table 2 Risk factors for complex abdominal wall hernia (number of patients (percentage))

\begin{tabular}{ll}
\hline Abdominal aortic aneurysm & $1(4.3 \%)$ \\
Anticoagulation therapy & $2(8.7 \%)$ \\
Chronic use of cortisone & $1(4.3 \%)$ \\
No other risk factors & $7(30.4 \%)$ \\
Personal history of previous abdominal wall hernia operation & $9(39.1 \%)$
\end{tabular}

\section{Quality-of-life parameters}

Patients reported a good quality of life on the EuraHS qualityof-life questionnaires (Table 3). The quality-of-life data are presented as median scores. Patients had no pain in rest or during activities, and the worst pain they had felt in the last week was no pain, although one patient $(4.3 \%)$ reported a pain score of 10 . Most patients had no restriction in their daily activities. They experienced only minor limitations in their activities outside the house. Three patients, however, reported severe restrictions in their daily activities (13.1\%). Patients that were capable of doing sports or heavy labor experienced limited restrictions. However, in the latter two situations, there were six and seven patients, respectively, that could not perform these activities.

\section{Discussion}

These results show that despite a high rate of postoperative wound infection no biological mesh had to be removed. Both the recurrence rate and the amount of bulging after long-term follow-up are significant (failure rate of $47.8 \%$ ). The reported quality of life is good after repair of these complex hernias.

The use of biological mesh in complex abdominal wall hernia is relatively new. There are not that many studies comparable with ours regarding methodology and characteristics. The RICH study, in which the results of Strattice ${ }^{\mathrm{TM}}$ mesh (Acelity ${ }^{\mathrm{TM}}$, non-cross-linked, acellular porcine dermis) were analyzed, seems to have the most similarities in methodological approach [31]. Itani et al. found a recurrence rate of $28 \%$ after 2 years [31]. This is comparable with the outcome of this study (26.1\%). In the study of Maxwell et al. [43], a much 
Table 3 Outcomes measured with the EuraHS quality-of-life scale $[33,34]$ after complex abdominal wall hernia repair with PADM. Scores are expressed as median scores (range)

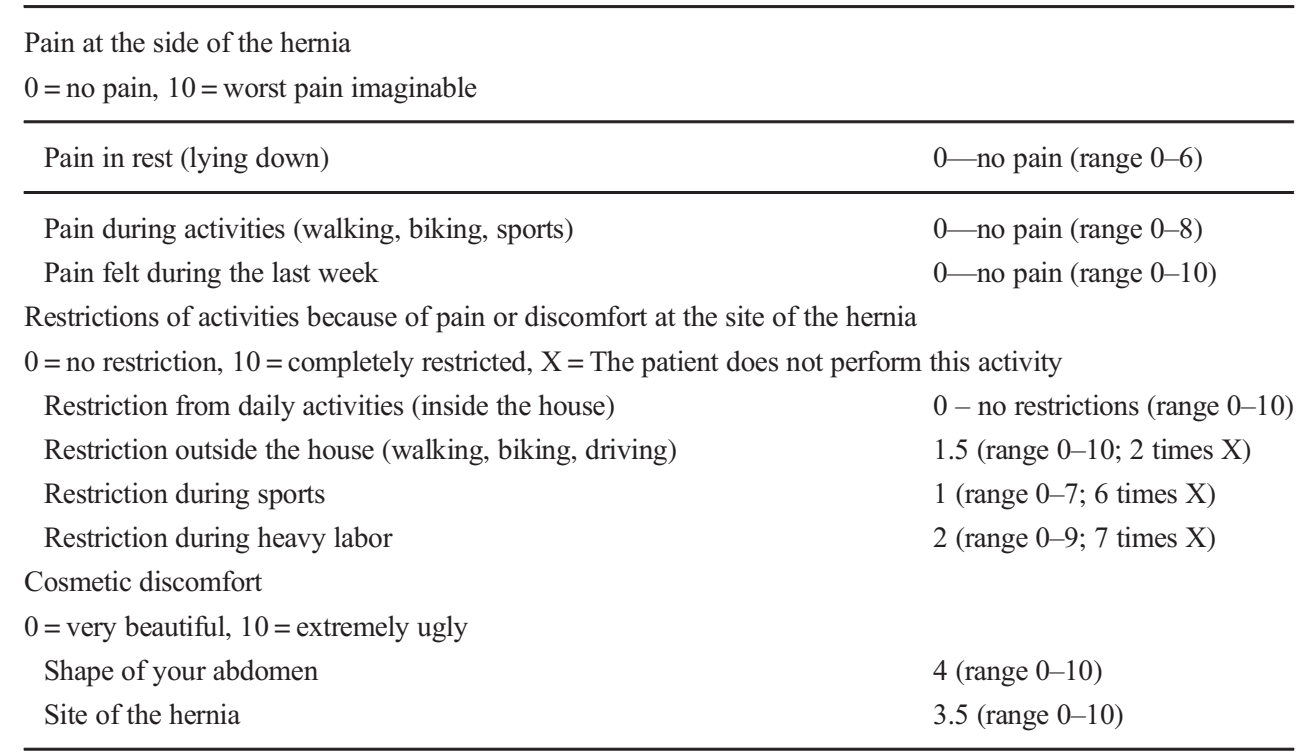

lower recurrence rate of $11.2 \%$ was found after median 20.9 months. Patients received an additional CT scan to confirm recurrence. Patients with bulging were excluded from the study. This could lead to certain bias, since bulging is also an unfavorable outcome. In a study by Rosen et al., a much higher recurrence rate of over 50\% was found after 3 years of follow-up. In Rosen's study, the following meshes were assessed: Strattice ${ }^{\mathrm{TM}}$ (same mesh; non-cross-linked porcine dermal matrix), Alloderm ${ }^{\mathrm{TM}}$ (non-cross-linked human dermal matrix), Biodesign $®$ (porcine small intestinal submucosa sheet), XenMatrix ${ }^{\mathrm{TM}}$ (non-cross-linked porcine dermal matrix), and BioA® (biosynthetic web scaffold made of $67 \%$ polyglycolic acid (PGA): $33 \%$ trimethylene carbonate) [44]. This high recurrence rate could possibly be explained by a longer follow-up. Another difference is the use of a number of different meshes, which could also lead to a higher recurrence rate. Also Itani et al. did not assess the amount of bulging in their study [31]. In this study, a bulging rate of $21.7 \%$ was found. This bulging rate is lower compared with data of a previous study from our study group (bulging rate $50.6 \%$ [45]). This difference could be explained by the difference in material, cross-linked versus non-cross-linked porcine acellular dermal matrix.

The patients that were enrolled in this study were operated in three hospitals in Germany. Each hospital had at least one surgeon dedicated to abdominal wall surgery. These surgeons treated their patients with PADM. The surgeons also united themselves in the ROKI group to assess their results of PADM repair [32]. Aside from the multicenter character of the study, another important asset was the assessment of quality-of-life parameters. This is only rarely studied in complex abdominal wall hernia repair. These patients suffer not only from a complex abdominal wall hernia but also of multiple comorbidities and risk factors that increase the risk of postoperative complications. A previous study of Roth et al. published about quality-of-life parameters in this specific patient group [46]. In this study, they used the short form-12 health survey [47] and found an improvement of the quality-of-life indicators after 12 months compared with the baseline. This improvement, however, was not significant. In the current study, no comparison was made with the preoperative situation, since these data were not prospectively obtained.

The most frequent postoperative complication in this study was wound infection (39.1\%). This percentage is slightly lower than in a recent study of Roth et al. [46]. Roth et al. found $43 \%$ wound infections after acellular dermal matrix placement (FlexHD® and Strattice ${ }^{\mathrm{TM}}$ ). The median follow-up was 1 year. The wound infection percentage in our study, however, was somewhat higher than previous studies by Itani el al. [31] (35\%), Diaz et al. [48] (33\%), Maxwell et al. [43] (26.2\%), Helton et al. [49] (23\%), and Cheng et al. [50] (5\%). All studies [31, 43, 48-50] contained a high percentage of patients that had a hernia classified as clean or clean contaminated [27]. In contrast to our cohort with only contaminated hernias, this could have led to a lower postoperative infection rate. In this study, PADM did not have to be removed representing a better result than found in the studies of Diaz et al. [48] (five mesh removals; 6.7\%) and Helton et al. [49] (five mesh removals; $9.8 \%$ ).

There is contrasting evidence available regarding biological meshes and their characteristics. A recent review by Sainfort et al. [51] assessed the literature about biologic abdominal wall matrices. They concluded that there were no high-level evidence data on biologic prostheses that allowed prioritization of the various biologic prostheses according to their characteristics or their different manufacturing processes. 
A more recent study by Tripolli et al. [52] assessed the literature on Permacol ${ }^{\mathrm{TM}}$, Strattice ${ }^{\mathrm{TM}}$, Surgisis ${ }^{\circledR}$, Tutomesh ${ }^{\mathrm{TM}}$, and XenMatrix $^{\mathrm{TM}}$. Eleven studies of a poor methodological quality were assessed and included in the review. They concluded that there was a striking statistical variability in the outcomes of all meshes. The only significant finding in their study was that cross-linked meshes had a significantly lower recurrence rate at 12 months than non-cross-linked meshes.

Incisional hernia repair is associated with overall financial losses [53]. Especially biological meshes are expensive and rarely used [54]. In the current study, no cost analysis was performed. In a study of Huntington et al., a cost analysis was performed comparing AlloDerm ${ }^{\circledR}$, AlloMax ${ }^{\mathrm{TM}}$, FlexHD ${ }^{\circledR}$, Strattice ${ }^{\mathrm{TM}}$, and XenMatrix ${ }^{\mathrm{TM}}$ [55]. In that study, Strattice ${ }^{\mathrm{TM}}$ was the second most expensive mesh (mesh charge per patient US\$ 31,875 \pm 17,960 and total costs hospital stay per patient US\$ $140,394 \pm 80,709)$. The mesh charges and total costs of hospital stay per patient seem higher in the USA than they are in the The Netherlands and Germany; however, these data are illustrative for the current ratios. In another study by Byrge et al., a head-to-head comparison was performed between Permacol ${ }^{\mathrm{TM}}$ and Strattice ${ }^{\mathrm{TM}}$ meshes in a similar patient group. The costs of the mesh were significantly higher for Strattice ${ }^{\mathrm{TM}}$ (median cost \$8940) compared with Permacol $^{\mathrm{TM}}$ (median costs $\$ 1600$ ). The use of Permacol ${ }^{\mathrm{TM}}$ resulted in a savings of $\$ 181,320$ with similar clinical outcomes when compared with Strattice ${ }^{\mathrm{TM}}[56]$.

\section{Limitations}

The mesh in this study (PADM) is not used on a large scale, and therefore there is only a limited number of patients that can be assessed. As only patients with potentially contaminated and contaminated abdominal wall hernia were evaluated, there was only a relatively small patient number to include in this study. Although there were more hospitals that work with PADM, not all surgeons seemed that keen to share their data. Another limitation is the design of the study (a cross-sectional cohort study). Data were partly retrospective and partly prospectively collected. This could have led to a bias.

\section{Conclusion}

The data of this study show that despite a high rate of postoperative wound infection, no biological mesh had to be removed. There was a high failure rate of $47.8 \%$ due to recurrences and bulging. However, patients reported a good quality of life after repair of these complex hernias without relevant limitation in everyday life activities.
Acknowledgments The authors would like to thank all the patients and hospitals that participated in this study.

Authors' contributions Ruth Kaufmann: Study conception and design, acquisition of data, analysis and interpretation of data, drafting of manuscript, critical revision of manuscript. Friedrich-Eckart Isemer: Study conception and design, acquisition of data, critical revision of manuscript. Christoph W. Strey: Study conception and design, acquisition of data, critical revision of manuscript. Johannes Jeekel: Study conception and design, analysis and interpretation of data, critical revision of manuscript. Johan F. Lange: Study conception and design, analysis and interpretation of data, critical revision of manuscript. Guido Woeste: Study conception and design, acquisition of data, analysis and interpretation of data, critical revision of manuscript.

Funding information This study was supported with a grant of LifeCell. LifeCell was bought by Allergan; grant number IIT-2017-10051. The mentioned company was not involved in the design of the study, the acquisition of data, the analysis of the results or the preparation of the manuscript.

\section{Compliance with ethical standards}

Conflict of interest The authors declare that they have no conflict of interest.

Ethical approval All procedures performed in studies involving human participants were in accordance with the ethical standards of the institutional and/or national research committee and with the 1964 Helsinki declaration and its later amendments or comparable ethical standards.

Informed consent Informed consent was obtained from all individual participants included in the study.

Open Access This article is licensed under a Creative Commons Attribution 4.0 International License, which permits use, sharing, adaptation, distribution and reproduction in any medium or format, as long as you give appropriate credit to the original author(s) and the source, provide a link to the Creative Commons licence, and indicate if changes were made. The images or other third party material in this article are included in the article's Creative Commons licence, unless indicated otherwise in a credit line to the material. If material is not included in the article's Creative Commons licence and your intended use is not permitted by statutory regulation or exceeds the permitted use, you will need to obtain permission directly from the copyright holder. To view a copy of this licence, visit http://creativecommons.org/licenses/by/4.0/.

\section{References}

1. Anthony T, Bergen PC, Kim LT, Henderson M, Fahey T, Rege RV et al (2000) Factors affecting recurrence following incisional herniorrhaphy. World J Surg 24(1):95-100 discussion 1

2. Hoer J, Lawong G, Klinge U, Schumpelick V (2002) Factors influencing the development of incisional hernia. A retrospective study of 2,983 laparotomy patients over a period of 10 years. Chirurg. 73(5):474-480

3. Manninen MJ, Lavonius M, Perhoniemi VJ (1991) Results of incisional hernia repair. A retrospective study of 172 unselected hernioplasties. Eur J Surg 157(1):29-31

4. Mudge M, Hughes LE (1985) Incisional hernia: a 10 year prospective study of incidence and attitudes. Br J Surg 72(1):70-71 
5. Paul A, Korenkov M, Peters S, Kohler L, Fischer S, Troidl H (1998) Unacceptable results of the Mayo procedure for repair of abdominal incisional hernias. Eur J Surg 164(5):361-367

6. Read RC, Yoder G (1989) Recent trends in the management of incisional herniation. Arch Surg 124(4):485-488

7. van Ramshorst GH, Eker HH, Hop WC, Jeekel J, Lange JF (2012) Impact of incisional hernia on health-related quality of life and body image: a prospective cohort study. Am J Surg 204(2):144-150

8. Adye B, Luna G (1998) Incidence of abdominal wall hernia in aortic surgery. Am J Surg 175(5):400-402

9. Augestad KM, Wilsgaard T, Solberg S (2002) Incisional hernia after surgery for abdominal aortic aneurysm. Tidsskr Nor Laegeforen 122(1):22-24

10. Bevis PM, Windhaber RA, Lear PA, Poskitt KR, Earnshaw JJ, Mitchell DC (2010) Randomized clinical trial of mesh versus sutured wound closure after open abdominal aortic aneurysm surgery. Br J Surg 97(10):1497-1502

11. Curro G, Centorrino T, Low V, Sarra G, Navarra G (2012) Longterm outcome with the prophylactic use of polypropylene mesh in morbidly obese patients undergoing biliopancreatic diversion. Obes Surg 22(2):279-282

12. Hall KA, Peters B, Smyth SH, Warneke JA, Rappaport WD, Putnam CW, Hunter GC (1995) Abdominal wall hernias in patients with abdominal aortic aneurysmal versus aortoiliac occlusive disease. Am J Surg 170(6):572-575 discussion 5-6

13. Holland AJ, Castleden WM, Norman PE, Stacey MC (1996) Incisional hernias are more common in aneurysmal arterial disease. Eur J Vasc Endovasc Surg 12(2):196-200

14. Israelsson LA, Jonsson T (1997) Overweight and healing of midline incisions: the importance of suture technique. Eur J Surg 163(3): 175-180

15. Puzziferri N, Austrheim-Smith IT, Wolfe BM, Wilson SE, Nguyen NT (2006) Three-year follow-up of a prospective randomized trial comparing laparoscopic versus open gastric bypass. Ann Surg 243(2):181-188

16. Raffetto JD, Cheung Y, Fisher JB, Cantelmo NL, Watkins MT, Lamorte WW et al (2003) Incision and abdominal wall hernias in patients with aneurysm or occlusive aortic disease. J Vasc Surg 37(6):1150-1154

17. Stevick CA, Long JB, Jamasbi B, Nash M (1988) Ventral hernia following abdominal aortic reconstruction. Am Surg 54(5):287289

18. Sugerman HJ, Kellum JM Jr, Reines HD, DeMaria EJ, Newsome HH, Lowry JW (1996) Greater risk of incisional hernia with morbidly obese than steroid-dependent patients and low recurrence with prefascial polypropylene mesh. Am J Surg 171(1):80-84

19. Sugerman HJ, Sugerman EL, Wolfe L, Kellum JM Jr, Schweitzer MA, DeMaria EJ (2001) Risks and benefits of gastric bypass in morbidly obese patients with severe venous stasis disease. Ann Surg 234(1):41-46

20. Burger JW, Luijendijk RW, Hop WC, Halm JA, Verdaasdonk EG, Jeekel J (2004) Long-term follow-up of a randomized controlled trial of suture versus mesh repair of incisional hernia. Ann Surg 240(4):578-583 discussion 83-5

21. Luijendijk RW, Hop WC, van den Tol MP, de Lange DC, Braaksma MM, IJ JN et al (2000) A comparison of suture repair with mesh repair for incisional hernia. N Engl J Med 343(6):392-398

22. Cevasco M, Itani KM (2012) Ventral hernia repair with synthetic, composite, and biologic mesh: characteristics, indications, and infection profile. Surg Infect 13(4):209-215

23. FitzGerald JF, Kumar AS (2014) Biologic versus synthetic mesh reinforcement: what are the pros and cons? Clin Colon Rectal Surg 27(4):140-148

24. Todros S, Pavan PG, Natali AN (2017) Synthetic surgical meshes used in abdominal wall surgery: part I-materials and structural conformation. J Biomed Mater Res B Appl Biomater 105(3):689-699
25. Cobb GA, Shaffer J (2005) Cross-linked acellular porcine dermal collagen implant in laparoscopic ventral hernia repair: casecontrolled study of operative variables and early complications. Int Surg 90(3 Suppl):S24-S29

26. Slade DA, Carlson GL (2013) Takedown of enterocutaneous fistula and complex abdominal wall reconstruction. Surg Clin North Am 93(5):1163-1183

27. Ventral Hernia Working G, Breuing K, Butler CE, Ferzoco S, Franz M, Hultman CS et al (2010) Incisional ventral hernias: review of the literature and recommendations regarding the grading and technique of repair. Surgery. 148(3):544-558

28. Chung L, Tse GH, O'Dwyer PJ (2014) Outcome of patients with chronic mesh infection following abdominal wall hernia repair. Hernia 18(5):701-704

29. Slater NJ, Montgomery A, Berrevoet F, Carbonell AM, Chang A, Franklin M, Kercher KW, Lammers BJ, Parra-Davilla E, Roll S, Towfigh S, van Geffen E, Conze J, van Goor H (2014) Criteria for definition of a complex abdominal wall hernia. Hernia 18(1):7-17

30. Iacco A, Adeyemo A, Riggs T, Janczyk R (2013) Single institutional experience using biological mesh for abdominal wall reconstruction. Am J Surg

31. Itani KM, Rosen M, Vargo D, Awad SS, Denoto G 3rd, Butler CE et al (2012) Prospective study of single-stage repair of contaminated hernias using a biologic porcine tissue matrix: the RICH study. Surgery. 152(3):498-505

32. Woeste G, Isemer FE, Strey CW, Schardey HM, Thielemann H, Mihaljevic A, Kleef J (2015) Use of biological meshes in abdominal wall reconstruction. Results of a survey in Germany. Chirurg. 86(2):164-171

33. Muysoms F, Campanelli G, Champault GG, DeBeaux AC, Dietz UA, Jeekel J et al (2012) EuraHS: the development of an international online platform for registration and outcome measurement of ventral abdominal wall hernia repair. Hernia 16(3):239-250

34. Muysoms FE, Vanlander A, Ceulemans R, Kyle-Leinhase I, Michiels M, Jacobs I, Pletinckx P, Berrevoet F (2016) A prospective, multicenter, observational study on quality of life after laparoscopic inguinal hernia repair with ProGrip laparoscopic, selffixating mesh according to the European Registry for Abdominal Wall Hernias Quality of Life Instrument. Surgery. 160(5):13441357

35. von Elm E, Altman DG, Egger M, Pocock SJ, Gotzsche PC, Vandenbroucke JP et al (2007) The strengthening the reporting of observational studies in epidemiology (STROBE) statement: guidelines for reporting observational studies. Lancet. 370(9596): 1453-1457

36. Korenkov M, Paul A, Sauerland S, Neugebauer E, Arndt M, Chevrel JP, Corcione F, Fingerhut A, Flament JB, Kux M, Matzinger A, Myrvold HE, Rath AM, Simmermacher RKJ (2001) Classification and surgical treatment of incisional hernia. Results of an experts' meeting. Langenbeck's Arch Surg 386(1): $65-73$

37. Heisterkamp J, den Hoed PT, Kluin J, Weidema WF, van Steensel CJ (2005) Long-term results after modified Gallie technique for incisional hernia repair: results in 19 patients. Hernia 9(1):12-15

38. Mitura K, Skolimowska-Rzewuska M, Garnysz K (2017) Outcomes of bridging versus mesh augmentation in laparoscopic repair of small and medium midline ventral hernias. Surg Endosc 31(1):382-388

39. Schoenmaeckers EJ, Wassenaar EB, Raymakers JT, Rakic S (2010) Bulging of the mesh after laparoscopic repair of ventral and incisional hernias. JSLS. 14(4):541-546

40. Dindo D, Demartines N, Clavien PA (2004) Classification of surgical complications: a new proposal with evaluation in a cohort of 6336 patients and results of a survey. Ann Surg 240(2):205-213

41. Garner JS (1986) CDC guideline for prevention of surgical wound infections, 1985. Supersedes guideline for prevention of surgical 
wound infections published in 1982. (Originally published in November 1985). Revised. Infect Control 7(3):193-200

42. Simmons BP (1983) Guideline for prevention of surgical wound infections. Am J Infect Control 11(4):133-143

43. Maxwell DW, Hart AM, Keifer OP, Jr., Halani SH, Losken A (2018) A comparison of acellular dermal matrices in abdominal wall reconstruction. Ann Plast Surg

44. Rosen MJ, Krpata DM, Ermlich B, Blatnik JA (2013) A 5-year clinical experience with single-staged repairs of infected and contaminated abdominal wall defects utilizing biologic mesh. Ann Surg 257(6):991-996

45. Kaufmann R, Timmermans L, van Loon YT, Vroemen J, Jeekel J, Lange JF (2019) Repair of complex abdominal wall hernias with a cross-linked porcine acellular matrix: cross-sectional results of a Dutch cohort study. Int J Surg 65:120-127

46. Roth JS, Zachem A, Plymale MA, Davenport DL (2017) Complex ventral hernia repair with acellular dermal matrices: clinical and quality of life outcomes. Am Surg 83(2):141-147

47. Ware J Jr, Kosinski M, Keller SD (1996) A 12-item short-form health survey: construction of scales and preliminary tests of reliability and validity. Med Care 34(3):220-233

48. Diaz JJ Jr, Guy J, Berkes MB, Guillamondegui O, Miller RS (2006) Acellular dermal allograft for ventral hernia repair in the compromised surgical field. Am Surg 72(12):1181-1187 discussion 7-8

49. Helton WS, Fisichella PM, Berger R, Horgan S, Espat NJ, Abcarian $\mathrm{H}$ (2005) Short-term outcomes with small intestinal submucosa for ventral abdominal hernia. Arch Surg 140(6):549-560 discussion 60-2
50. Cheng AW, Abbas MA, Tejirian T (2014) Outcome of abdominal wall hernia repair with biologic mesh: Permacol versus Strattice. Am Surg 80(10):999-1002

51. Sainfort A, Denis Hallouard I, Hartmann D, Aulagner G, Francois Y, Tiffet O, Barabino G, Nuiry O, Armoiry X (2016) Xenograft biologic mesh in parietal and general surgery: technical assessment and review of clinical effectiveness and safety data. J Visc Surg 153(6):403-417

52. Trippoli S, Caccese E, Tulli G, Ipponi P, Marinai C, Messori A (2018) Biological meshes for abdominal hernia: lack of evidencebased recommendations for clinical use. Int J Surg 52:278-284

53. Reynolds D, Davenport DL, Korosec RL, Roth JS (2013) Financial implications of ventral hernia repair: a hospital cost analysis. J Gastrointest Surg 17(1):159-166 discussion p 66-7

54. Darehzereshki A, Goldfarb M, Zehetner J, Moazzez A, Lipham JC, Mason RJ, Katkhouda N (2014) Biologic versus nonbiologic mesh in ventral hernia repair: a systematic review and meta-analysis. World J Surg 38(1):40-50

55. Huntington CR, Cox TC, Blair LJ, Schell S, Randolph D, Prasad T, Lincourt A, Heniford BT, Augenstein VA (2016) Biologic mesh in ventral hernia repair: outcomes, recurrence, and charge analysis. Surgery. 160(6):1517-1527

56. Byrge N, Mone MC, Vargo D (2017) Hospital wide porcine mesh conversion results in cost savings with equivalent clinical outcomes. Am J Surg 213(6):1042-1045

Publisher's note Springer Nature remains neutral with regard to jurisdictional claims in published maps and institutional affiliations. 